\title{
Enhanced Interleukin-6 and Interleukin-8 Synthesis in Term and Preterm Infants
}

\author{
CHRISTIAN SCHULTZ, CHRISTINA ROTT, PETRA TEMMING, PETER SCHLENKE, \\ JENS C. MÖLLER, AND PETER BUCSKY \\ Department of Pediatrics [C.S., C.R., P.T., J.C.M., P.B.], and Institute of Immunology and Transfusion \\ Medicine [P.S.], Medical University of Lübeck, Lübeck, Germany
}

\begin{abstract}
ABS
There is growing evidence that sepsis-related complications
in neonates are crucially mediated by the action of proinflam-
matory cytokines. It has previously been demonstrated that ele-
vated IL-6 and IL-8 levels can predict brain damage and chronic
lung disease in preterm infants. However, it is the current view
that neonates have a reduced capability to produce proinflamma-
tory cytokines. To clarify this issue, we analyzed the inflamma-
tory response in term and preterm infants directly at the single
cell level by flow cytometry. Endotoxin challenge was performed
under defined conditions on monocytes obtained from 50 healthy
adults and 119 neonates, which consist of 45 term infants, 63
preterm infants (26.1-36.7 wk of gestational age), and 11 pre-
term infants with proven infection (24.6-29.9 wk). Our results
challenge the existing view of an immature inflammatory re-
sponse by demonstrating that term infants and preterm infants
\end{abstract}
Neonatal bacterial sepsis remains a critical determinant of outcome in infants of very low birth weight despite the availability of antibiotics (1-3). The immaturity of the neonatal immune system, especially a reduced cytokine-producing capacity, was assumed to be responsible for the high susceptibility to infections (4-11). Particularly, the high prevalence of complications secondary to infections represents a major determinant of neonatal mortality and morbidity (3). Although older children and adults are usually able to restrict bacterial infections, neonates often develop a severe systemic inflammatory response with detrimental effects. There is growing evidence that this process is crucially mediated by the action of distinct inflammatory cytokines $(12,13)$. It has previously been demonstrated that elevated IL-6 and IL-8 levels in cord blood and lung lavage can predict neonatal brain damage and chronic lung disease in preterm infants (14-16). Furthermore, proinflammatory cytokines could be demonstrated in high amounts in brain white matter lesions of preterm infants (17). These

Received February 1, 2001; accepted September 25, 2001.

Correspondence and reprint requests: Christian Schultz, M.D., Department of Pediatrics, Medical University of Lübeck, Ratzeburger Allee 160, 23538 Lübeck, Germany; e-mail: ChrSchultz@aol.com

Supported in part by "Lübeck Hilfe für krebskranke Kinder e.V." display a higher percentage of IL-6 - and IL-8 - positive cells than adults. After preincubation with dexamethasone the number of cytokine-positive cells decreased in all groups, but the number of IL-8-positive cells remained higher in term and preterm infants $>32$ wk compared with adults. These observations demonstrate not only a well-developed but also an enhanced inflammatory response in term and preterm infants. Under consideration of several detrimental effects of IL-6 and IL-8, our data may have major implications on the pathophysiology of inflammatorytriggered neonatal diseases. (Pediatr Res 51: 317-322, 2002)

\section{Abbreviations}

HBSS, Hanks' balanced salt solution

LPS, lipopolysaccharide observations strongly suggest a key role of proinflammatory cytokines in the pathogenesis of several neonatal diseases. Although a variety of studies have been performed on inflammatory mediators in neonates during infection, these data can be misleading because of the evolving immunoparalysis occurring in progressing sepsis $(18,19)$. To better characterize the inflammatory response in neonates we performed an ex vivo model of sepsis, in which monocytes obtained from healthy term and preterm infants were stimulated under defined conditions. In contrast to previous studies with contradicting results, cytokines were analyzed directly at the cell level by flow cytometry after whole blood culture assay. Using this method, cellular interactions were preserved and cytokine production could be related to a specific cell type without performing a cell-separation procedure.

\section{METHODS}

Study population. Heparinized venous cord blood samples were obtained after informed consent and approval of the institutional review board from 74 preterm infants and 45 healthy term infants immediately after delivery. Thirty-six term infants were delivered spontaneously and nine by cesarean section. The male to female ratio was $24: 21$; the median 
birth weight, $3500 \mathrm{~g}$ (range, 2270-4640 g). The 1-min Apgar score was $>7$ in all term infants. Thirty-six preterm infants were older than (group P-1, Table 1) and 38 preterm infants $<32$ wk gestational age (groups P-2, P-3). Eleven preterm infants $<32$ wk had a proven infection and were analyzed separately (group P-3). Infection was defined as positive blood culture, elevated C-reactive protein, clinical signs of sepsis, or histopathologic evidence of chorioamnionitis. Fifty-five of 74 preterm infants $(74 \%)$ were treated with corticosteroids antenatally according to the National Institutes of Health consensus conference to accelerate fetal lung maturity (20). There was no evidence of congenital malformation. Patient characteristics are shown in Table 1.

Fifty healthy adult volunteers served as a control group (30 men; mean age, $31.2 \mathrm{y}$; range, 21-56 y). All blood samples were collected in lithium-heparin tubes (Sarstedt, Nürnbrecht, Germany) and were stored at room temperature for no longer than $24 \mathrm{~h}$ before processing.

Culture and stimulation of cells. Approximately $0.5 \mathrm{~mL}$ of heparinized whole blood was suspended in RPMI 1640 supplemented with $1 \%$ penicillin/streptomycin, $2 \mathrm{mM}$ glutamine, $1 \mathrm{mM}$ pyruvate, and nonessential amino acids (Seromed Biochrome, Berlin, Germany) at a concentration of $5 \times 10^{6}$ leukocytes $/ \mathrm{mL}$. Aliquots of blood were stimulated for $5 \mathrm{~h}$ in multiwell plates with $30 \mathrm{ng} / \mathrm{mL}$ LPS (Sigma Chemical Co., Deisenhofen, Germany) at $37^{\circ} \mathrm{C}, 5 \% \mathrm{CO}_{2}$, unless otherwise indicated. Cells were exposed to $3 \mu \mathrm{M}$ monensin (Sigma Chemical Co.) during the whole stimulation period to inhibit cytokine secretion. Dexamethasone was added $1 \mathrm{~h}$ before stimulation at a concentration of $10^{-7} \mathrm{M}$ and $10^{-5} \mathrm{M}$. After a washing step with HBSS (Seromed Biochrome), cultured cells

Table 1. Study population of preterm infants*

\begin{tabular}{lcll}
\hline \multicolumn{1}{c}{ Characteristics } & \multicolumn{1}{c}{ P-1 } & \multicolumn{1}{c}{ P-2 } & \multicolumn{1}{c}{ P-3 } \\
\hline Number of cases & 36 & 27 & 11 \\
Gestational age (wk, median) & 34.1 & 30.6 & 27.3 \\
$\quad$ (range) & $32.1-36.7$ & $26.1-31.9$ & $24.6-29.9$ \\
Birth weight (g, median) & 2180 & 1315 & 765 \\
$\quad$ (range) & $1135-3140$ & $625-2100$ & $520-1390$ \\
Male/female & $17 / 19$ & $11 / 16$ & $6 / 5$ \\
Cesarean delivery & $29(81 \%)$ & $27(100 \%)$ & $10(91 \%)$ \\
Corticosteroid pretreatment & $18(50 \%)$ & $26(96 \%)$ & $11(100 \%)$ \\
$\quad<24$ h before delivery & $1(3 \%)$ & $6(22 \%)$ & $2(18 \%)$ \\
$\quad<48$ h before delivery & $3(8 \%)$ & $13(48 \%)$ & $6(55 \%)$ \\
1-min Apgar score $<7$ & $1(3 \%)$ & $2(7 \%)$ & $3(27 \%)$ \\
Umbilical arterial pH $<7.1$ & $1(3 \%)$ & - & $1(9 \%)$ \\
Histologic chorioamnionitis & - & - & $6(55 \%)$ \\
CRP $>$ 15 mg/L & - & - & $5(46 \%)$ \\
Positive blood culture & - & - & $2(18 \%)$ \\
Respiratory distress syndrome & $5(14 \%)$ & $23(85 \%)$ & $8(73 \%)$ \\
Bronchopulmonary dysplasia $\dagger$ & - & - & $2(18 \%)$ \\
IVH I-II & $1(3 \%)$ & $4(15 \%)$ & - \\
IVH $>$ II & - & $1(4 \%)$ & - \\
Periventricular white matter lesions & - & $1(4 \%)$ & $1(9 \%)$ \\
Death before age 1 mo & - & $1(4 \%)$ & $2(18 \%)$ \\
\hline
\end{tabular}

* P-1, preterm infants $>32 \mathrm{wk}$; P-2, preterm infants $<32 \mathrm{wk}$; P-3, preterm infants $<32$ wk with proven infection.

$\dagger$ Bronchopulmonary dysplasia was defined according to Bancalari with oxygen need at day 28 of life (38).

Abbreviations used: CRP, C-reactive protein; IVH, intraventricular hemorrhage. were fixed in 4\% paraformaldehyde (Riedel de Haen, Seelze, Germany) for 10 min and resuspended in nonfat dry milk (5\%) for $16 \mathrm{~h}$ at $4^{\circ} \mathrm{C}$ in the dark.

Intracellular staining of cytokines. Cells were washed in HBSS and resuspended in a buffer consisting of HBSS, $0.1 \%$ saponin (Riedel de Haen), and 0.01 M HEPES buffer (Seromed Biochrome). Two hundred-microliter aliquots of cells were added to tubes containing $0.5 \mu \mathrm{g} / 10 \mu \mathrm{L}$ of MAbs against CD14 (M5E2, phycoerythrin-conjugated), IL-6 (MQ2-13A5, FITC-conjugated), and IL-8 (G265-8, FITC-conjugated; Pharmingen, Heidelberg, Germany). Preincubation with a surplus of unconjugated anti-cytokine MAbs $(5 \mu \mathrm{g} / 10 \mu \mathrm{L}$; Pharmingen) served as a negative control for intracellular staining to each sample. Isotype-specific antibodies were used to detect irrelevant specificity for surface molecule staining.

Flow cytometric analysis. Two-color flow cytometric analysis was performed on an EPICS XL flow cytometer with System II, Version 1.0 software (Coulter Electronics, Krefeld,

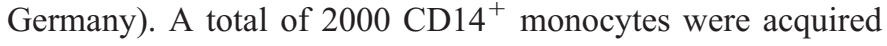
from each sample. Dead cells were excluded by forward and side scatter gating. Thresholds were set according to the purified antibody-blocking control. Positive cells $<2 \%$ were allowed beyond the statistical marker. Data were expressed as percentage of $\mathrm{CD} 14^{+}$monocytes producing each cytokine.

Statistical analysis. Statistical differences between all groups were first checked by the Kruskal-Wallis test. After confirmation of significance statistical differences between groups were tested by the nonparametric Mann-Whitney $U$ test. The level of significance was defined as $p<0.05$ in single comparisons. The level of significance was corrected according to Bonferroni in multiple comparisons among four groups ( $\alpha=$ $0.05 / 4=0.0125$ ). Data were expressed as median and interquartile range in parentheses, if not indicated otherwise. Correlation analysis was performed with Spearman's rank-order correlation coefficient $r$ and Fisher's exact test. Statistical analyses were performed using SPSS 9.0 statistical software (SPSS Inc., Chicago, IL, U.S.A.).

\section{RESULTS}

Increased spontaneous production of IL-6 and IL-8 in term and preterm infants. The percentage of IL-6-positive monocytes was strikingly lower than the percentage of IL-8positive monocytes without in vitro stimulation in all investigated groups. Term infants and preterm infants $>32 \mathrm{wk}$ show a higher percentage of IL-6-positive monocytes compared with adults $[1.8 \%(1.2-6 \%)$ and $2 \%(1.2-3.5 \%)$ versus $0.8 \%$ $(0.6-1.6 \%) ; p<0.0001]$. Furthermore, the percentage of IL-6-positive monocytes was higher in preterm infants $<32$ wk with proven infection compared with adults $[3.6 \%(1.4-$ $10.8 \%)$ versus $0.8 \%(0.6-1.6 \%) ; p<0.0001]$. Compared with preterm infants $<32$ wk the percentage of IL-6-positive monocytes was higher in the group of preterm infants with proven infection [3.6\% (1.4-10.8\%) versus $1.3 \%(1-2.7 \%) ; p$ $<0.01$; Fig. 1]. Preterm infants $<32$ wk display a comparable percentage of IL-6-positive cells without stimulation as adults $[1.3 \%(1-2.7 \%)$ versus $0.8 \%(0.6-1.6 \%) ; p=0.015]$. 
The differences were even more impressive for IL-8positive cells. Term infants and preterm infants $>32 \mathrm{wk}$ had a significantly higher percentage of IL-8-positive cells compared with adults $[7.2 \%(1.6-39.2 \%)$ and $8.6 \%(1.8-24.2 \%)$ versus $1.1 \%(0.3-2.5 \%) ; p<0.0001]$. Even preterm infants $<32$ wk had a higher percentage of IL-8-positive cells than adults [6\% (1.6-19.4\%) versus $1.1 \%(0.3-2.5 \%) ; p<0.0001]$. Moreover, preterm infants $<32 \mathrm{wk}$ with proven infection show the highest percentage of IL-8-positive monocytes [25.3\% (8.6-53.8\%) versus adults $1.1 \%(0.3-2.5 \%) ; p<0.0001$; Fig. 1].

Enhanced production of IL-6 and IL-8 in term and preterm infants after stimulation in vitro. After stimulation with LPS, term infants had a profoundly higher percentage of both IL-6 [63\% (57.1-69.5\%) versus 51.8\% (43.2-59.6\%); $p<$ $0.0001]$ and IL-8 compared with adults $[83.6 \%(75.6-88.1 \%)$ versus $68.9 \%$ (62.8-74.7\%); $p<0.0001]$. In addition, preterm infants $>32$ wk show a slightly higher percentage of IL-6 [57.6\% (50.7-66.7\%) versus 51.8\% (43.2-59.6\%); $p=0.016]$ and a strikingly higher percentage of IL-8-positive monocytes than adults as well $[79.5 \%(72.7-84.5 \%)$ versus $68.9 \%(62.8-$ $74.7 \%) ; p<0.0001]$. Preterm infants $<32$ wk had a lower percentage of IL-6-positive cells after LPS stimulation compared with adults [43.2\% (33.6-49.8\%) versus $51.8 \%$ (43.2$59.6 \%) ; p=0.002]$. However, the percentage of IL-8-positive monocytes was slightly higher than in adults $[75.4 \%$ (66.4$84.6 \%)$ versus $68.9 \%(62.8-74.7 \%) ; p=0.01]$. Preterm infants $<32$ wk with proven infection had a significantly higher percentage of IL-6-positive monocytes than preterm infants $<32$ wk without an infection [53.9\% (48.4-61.2\%) versus $43.2 \%(33.6-49.8 \%) ; p<0.01]$ and had a comparable percentage of IL-6-positive monocytes as adults $[53.9 \%$ (48.4$61.2 \%)$ versus $51.8 \%(43.2-59.6 \%) ; p=0.6]$. However, the

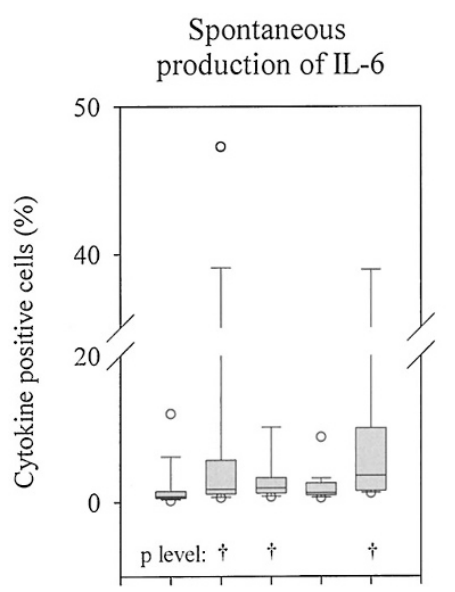

A $T$ P-1 P-2 P-3

Groups

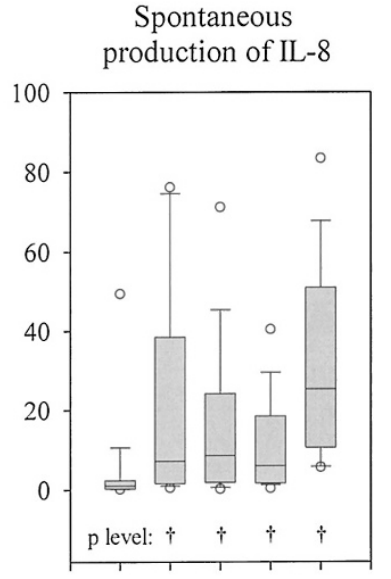

A $T$ P $-1 \quad P-2 \quad P-3$

Groups
Figure 1. Spontaneous cytokine production. The percentage of IL-6- and IL-8-positive monocytes was higher in term infants (T), preterm infants $>32$ wk (P-1) and preterm infants $<32$ wk with proven infection (P-3) compared with adults (A). Preterm infants $<32 \mathrm{wk}$ without an infection (P-2) display a comparable percentage of IL-6- and a higher percentage of IL-8-positive monocytes than adults. Differences were significant at $p<0.0001$ (†) compared with adults as indicated. Data were expressed as box plots showing the 10th, 25th, 50th, 75th, and 90th percentiles. percentage of IL-8-positive monocytes was strikingly higher in preterm infants with proven infection compared with adults [88.3\% (75.8-91.4\%) versus $68.9 \%(62.8-74.7 \%) ; p<$ 0.0001; Fig. 2].

IL-6 but not IL-8 production correlates positively to gestational age. There was a moderately positive relation between gestational age and the percentage of IL-6-positive monocytes after endotoxin challenge in vitro $(r=0.55 ; p<0.01)$. However, there was no correlation between IL-8-positive monocytes and gestational age $(r=0.12)$, indicating already a high production of IL- 8 in very premature infants.

Influence of labor on cytokine production. After correction for gestational age infants delivered spontaneously were compared with infants delivered by elective cesarean section. In preterm infants $>32$ wk there was no correlation between the percentage of IL-6 - and IL-8 - positive monocytes and delivery mode. The comparison could not be performed in term infants and preterm infants $<32$ wk because the number of elective cesarean section in term infants without onset of labor was too small and all preterm infants $<32$ wk were delivered by cesarean section.

Faster inflammatory response in term infants. After $3 \mathrm{~h}$ of stimulation the percentage of IL-6-positive monocytes was higher in neonates than adults $(p<0.05 ; n=5)$. The percentage of IL-8-producing monocytes was already higher after $1 \mathrm{~h}$ of stimulation in neonates compared with adults and remained above that for adults during the following stimulation period $(p$ $<0.05 ; n=5$ ). IL-8 - positive monocytes had a maximum peak at $3 \mathrm{~h}$ followed by a decline thereafter in both neonates and
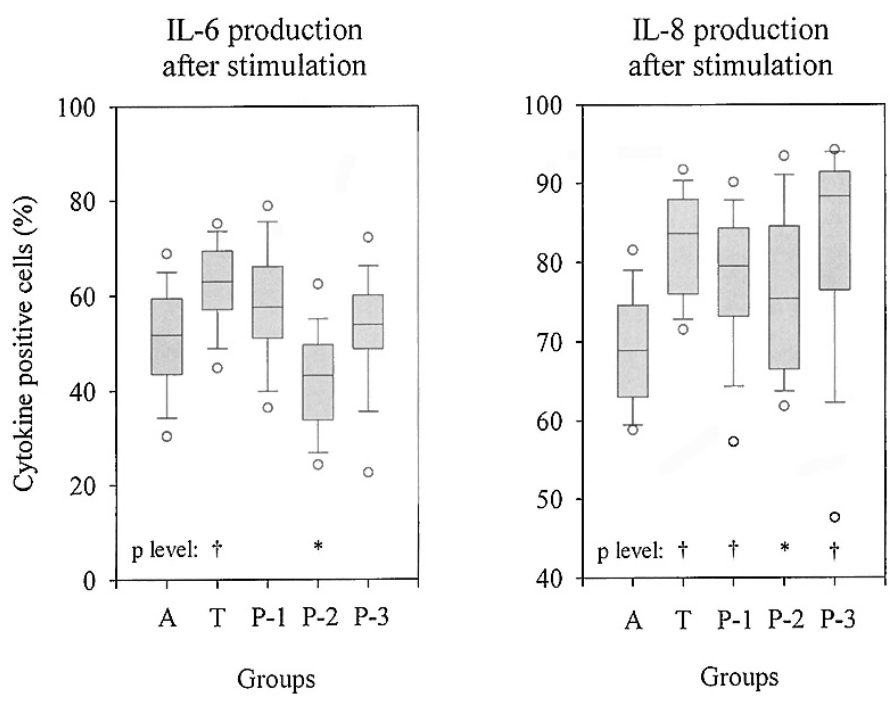

Figure 2. Cytokine production after endotoxin challenge with LPS. The percentage of IL-6- and IL-8-positive monocytes was higher in term infants $(\mathrm{T})$ compared with adults (A). All preterm infants (P-1, P-2, P-3) show a higher percentage of IL-8-positive monocytes than adults. The percentage of IL-6-positive cells in preterm infants $>32$ wk (P-1) was slightly but not significantly higher than in adults and comparable between adults and preterm infants with proven infection (P-3). Preterm infants $<32$ wk (P-2) show a lower percentage of IL-6-positive monocytes than adults. Differences were significant at $p<0.01(*)$ or $p<0.0001(\dagger)$ compared with adults as indicated. Data were expressed as box plots showing the 10th, 25th, 50th, 75th, and 90th percentiles. 
adults, indicating a decreasing capacity to produce IL-8 during stimulation with LPS (Fig. 3).

Influence of corticosteroid pretreatment on IL-6 and IL-8 production. There was no effect of antenatally corticosteroid treatment on IL-6 - and IL-8 -positive monocytes without stimulation ( $p=0.7$ and $p=0.5$, respectively) and IL-8-positive monocytes after stimulation with LPS $(p=0.1)$ in preterm infants without an infection (P-1, P-2). The percentage of IL-6-positive cells after stimulation with LPS was lower in preterm infants treated antenatally with corticosteroids $(n=$ 44) compared with preterm infants without corticosteroid pretreatment $[n=19 ; 48.3 \%$ (39.9-54.4\%) versus $63.4 \%$ (53.6$72.4 \%) ; p<0.0001]$. However, most preterm infants without corticosteroid pretreatment were $>32$ wk (18 of $19 ; 95 \%$ ) whereas treated preterm infants were primarily $<32 \mathrm{wk}$ ( 26 of $44 ; 59 \%)$. For ethical reasons both groups could not be matched according to gestational age. Therefore, the lower percentage of IL-6-positive monocytes after stimulation with LPS in the group of pretreated preterm infants could also be the result of the lower gestational age.

Inhibition of IL-6 and IL-8 production by dexamethasone in vitro. Whole blood was incubated with dexamethasone for $1 \mathrm{~h}$ before stimulation with LPS. The concentrations used represent serum levels of low birth weight infants treated with the commonly used doses of dexamethasone to prevent chronic lung disease $(0.3-0.4 \mathrm{mg} / \mathrm{kg})(21)$. There was a dose-related inhibition of cytokine-positive cells with a profoundly stronger reduction of IL-6- (range, 43-80\%) than IL-8-positive monocytes (range, $17-67 \%$ ) in all investigated groups. The decline of IL-6- (mean, 74\% versus 50\%; $p=0.03$ ) and IL-8-positive cells $(55 \%$ versus $26 \%$; $p=0.03)$ was highest in preterm infants $<32$ wk compared with adults using $10^{-7} \mathrm{M}$ dexamethasone. The decline of IL-6-positive cells was comparable in term infants, preterm infants $>32 \mathrm{wk}$ and adults after preincubation with dexamethasone. Surprisingly, IL-8-positive monocytes remained higher despite preincubation with $10^{-5} \mathrm{M}$
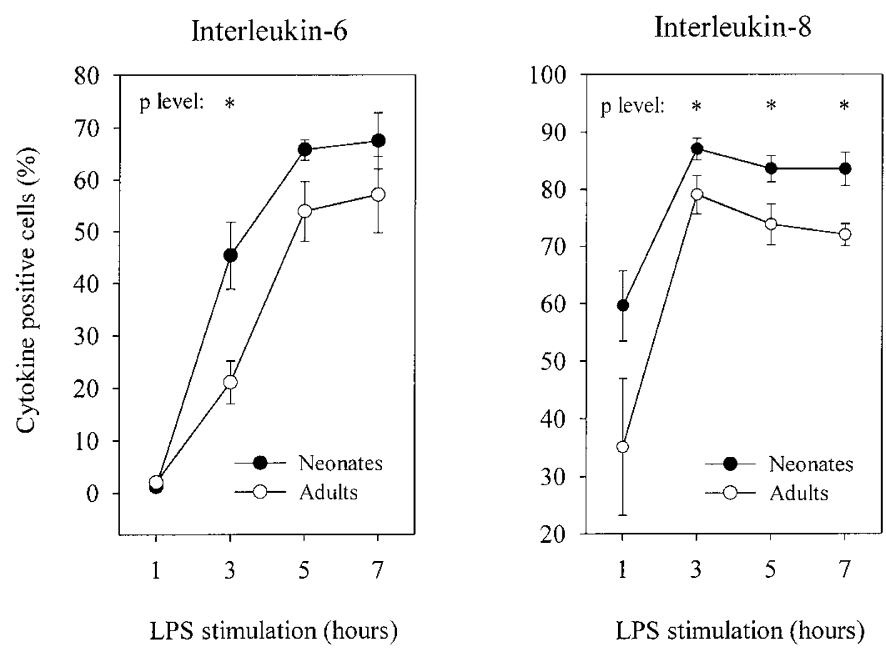

Figure 3. Kinetics of cytokine production. Neonatal monocytes display a strikingly faster production of both cytokines compared with adults. The percentage of IL-6- and IL-8-positive monocytes in neonates was higher already after $3 \mathrm{~h}$ and $1 \mathrm{~h}$ of stimulation with LPS, respectively $(n=5)$. Differences were significant at $p<0.05(*)$ as indicated. dexamethasone in term infants (reduction rate, $37 \%$ versus $62 \% ; p<0.005)$ and preterm infants $>32$ wk compared with adults $(35 \%$ versus $62 \%$; $p=0.005$; Fig. 4$)$.

\section{DISCUSSION}

There is growing evidence that the fetal inflammatory response plays a major role in the induction of several neonatal diseases (12-17). However, the capability of newborn infants to produce inflammatory cytokines has been considered immature (4-11). This is contradictory to the clinical observation that neonates can develop a severe systemic inflammatory response during sepsis $(13,22,23)$. Although studies have been performed on proinflammatory cytokines during infection in neonates, these data are misleading because cytokine production can be impaired by a phenomenon called immunoparalysis occurring in progressing sepsis $(18,19)$. This phenomenon could be demonstrated in infants on the second day of infection (data not shown) and in kinetic studies that revealed a decline of IL-8 production after $3 \mathrm{~h}$ of stimulation with LPS in both neonates and adults (Fig. 3). Furthermore, different kinds of stimulation procedures and techniques used may contribute to the impaired production of cytokines demonstrated in previous studies (4-11). To circumvent these pitfalls, we preferred a standardized ex vivo model of sepsis rather than investigating septic neonates at different times during the inflammatory cascade. In vitro endotoxin challenge was performed under defined conditions on monocytes obtained from healthy neonates. Cytokine production was analyzed directly at the cell level by flow cytometry. This method has been demonstrated as a reliable and sensitive technique $(24,25)$ that enables a direct relation between cytokine production and cell phenotype without performing cell-separation procedures (26).
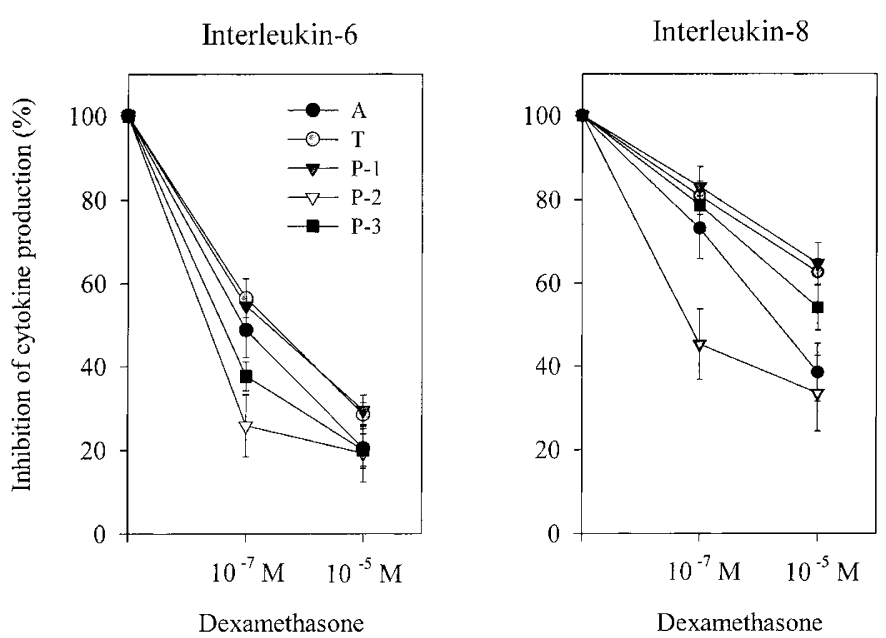

Figure 4. Inhibition of cytokine synthesis by dexamethasone. Dexamethasone induced a dose-related inhibition of cytokine synthesis with a profoundly stronger reduction of IL-6 - than IL-8-positive monocytes in all investigated groups. Preterm infants $<32 \mathrm{wk}$ display the strongest inhibition of cytokinepositive cells by $10^{-7} \mathrm{M}$ dexamethasone (P-2). The percentage of IL-6positive monocytes was comparable in term infants $(\mathrm{T})$, preterm infants $>32$ wk (P-1), and adults (A) after preincubation with dexamethasone. Despite preincubation with $10^{-5} \mathrm{M}$ dexamethasone, the percentage of IL-8-positive monocytes was significantly higher in term infants and preterm infants $>32 \mathrm{wk}$ compared with adults. 
This is mandatory because functional responses of purified cell preparations may not represent physiologic reactions occurring in vivo (27). Furthermore, a dissociation between plasma and cell-associated cytokines during sepsis (28) warrants cytokine analysis at the single cell level.

In contrast to the current view (4-11), we found an unexpectedly high percentage of IL-6 - and IL-8-positive cells in term and preterm infants. Remarkably, cytokine production was even higher both spontaneously and after endotoxin challenge compared with adults. This is of special concern because both cytokines were linked to the induction of several neonatal diseases $(12,13)$. Elevated levels of IL-6 and IL-8 in umbilical cord plasma and amniotic fluid predict not only imminent preterm delivery but also cerebral white matter damage, bronchopulmonary dysplasia, cerebral palsy, intraventricular hemorrhage, and necrotizing enterocolitis $(13,29-31)$. It has been shown that maternal endotoxin administration induces a dosedependent cytokine increase in the fetal rat brain (32). In several animal models IL- 6 was able to affect the integrity of the blood-brain barrier and to induce brain injury (33-35). In preterm infants a breakdown of a still immature blood-brain barrier may be important in the pathophysiology of the dreaded complication of intraventricular hemorrhage. Furthermore, proinflammatory cytokines could be demonstrated in high amounts in brain lesions of preterm infants (16), suggesting a key role of these mediators in the pathogenesis of brain damage of preterm infants. Brain injury peaks at a younger conceptional age and displays a diffuse pattern compared with the focal lesions in term infants. It has been suggested that diffuse brain injury of the very low birth weight infant is the result of an increased vulnerability, characterized by an immature blood-brain barrier, incomplete myelination, and suboptimal levels of endogenous protectors (36). Effects of proinflammatory cytokines may be even more hazardous under consideration of this increased vulnerability of the premature infant.

In the presented study we can demonstrate not only a well-developed but also an enhanced spontaneous production of the proinflammatory cytokines IL- 6 and IL- 8 directly at the cell level in term and preterm infants (Fig. 1). After endotoxin challenge both cytokines were higher in term and preterm infants $>32 \mathrm{wk}$ than in adults despite corticosteroid pretreatment in 18 of 36 preterm infants (Fig. 2). Furthermore, kinetic studies revealed a remarkably faster production of both cytokines in term neonates compared with adults (Fig. 3).

After endotoxin challenge preterm infants $<32$ wk show a lower percentage of IL-6-positive monocytes but a higher percentage of IL-8-positive monocytes than adults. However, these very low birth weight infants were treated with corticosteroids antenatally to accelerate fetal lung maturity in 26 of 27 infants. Therefore, the reduced number of IL-6-positive cells after endotoxin challenge could also be the result of corticosteroid pretreatment. For ethical reasons a control group without corticosteroid treatment could not be recruited. Nonetheless, it is even more amazing that these very low birth weight infants display a higher percentage of IL-8-positive monocytes than adults despite pretreatment with corticosteroids. Furthermore, these very low birth weight infants show a comparable percentage of IL-6-positive cells and a higher percent- age of IL-8-positive cells than adults during infection. These observations demonstrate that the most vulnerable preterm infants were capable of producing proinflammatory cytokines during infection as well.

To investigate the impact of corticosteroid treatment on the enhanced inflammatory response monocytes were preincubated with dexamethasone in vitro. There was a dose-related inhibition of cytokine synthesis with a profoundly stronger decline of IL-6 - than IL-8-positive cells in all investigated groups. Very low birth weight infants $<32$ wk display the strongest inhibition of cytokine-positive cells by $10^{-7} \mathrm{M}$ dexamethasone. However, the percentage of IL-8-positive monocytes was significantly greater in term and preterm infants $>32$ wk compared with adults using $10^{-5} \mathrm{M}$ dexamethasone (Fig. 4), supporting the hypothesis of an exaggerated proinflammatory response in neonates after endotoxin challenge. From these data, we hypothesize that the fetal inflammatory response may be more important in the pathogenesis of several neonatal diseases than previously suspected.

Considering a diminished production of the antiinflammatory cytokine IL-10 in neonates $(15,37)$, a defective downregulation of inflammation may contribute to the enhanced proinflammatory cytokine synthesis in term and preterm infants demonstrated in our study. In view of that, the high incidence of severe complications, such as sepsis in term infants and brain injury, bronchopulmonary dysplasia, and necrotizing enterocolitis in preterm infants during infection (3, 13), may be initiated by the inability to control inflammation. For that reason, we hypothesize that an imbalance between pro- and antiinflammatory cytokines in favor of the proinflammatory cascade plays a major role in the pathophysiology of several neonatal diseases in addition to the increased vulnerability of developing organ systems in preterm infants.

In conclusion, we refuted the current view that the inflammatory response in preterm infants is immature. On the contrary, an enhanced production of proinflammatory cytokines could be demonstrated both spontaneously and after endotoxin challenge directly at the cell level in term and preterm infants. Considering several detrimental effects of proinflammatory cytokines, our data may have major implications in the understanding of neonatal inflammatory diseases and may offer a basis for therapeutic interventions perhaps in the near future.

\section{REFERENCES}

1. Klein JO, Marcy SM 1995 Bacterial sepsis and meningitis. In: Remington JS, Klein JO (eds) Infectious Diseases of the Fetus and Newborn Infant. WB Saunders, Philadelphia, pp 846-851

2. LaGamma EF, Drusin LM, Mackles AW, Machalek S, Auld PAM 1983 Neonatal infections: an important determinant of late NICU mortality in infants $<1000 \mathrm{~g}$ at birth. Am J Dis Child 137:838-841

3. Martinot A, Leclerc F, Cremer R, Leteurtre S, Fourier C, Hue V 1997 Sepsis in neonates and children: definitions, epidemiology, and outcome. Pediatr Emerg Care $13: 277-281$

4. Chang M, Suen Y, Lee S, Baly D, Buzby JS, Knoppel E, Wolpe S, Cairo MS 1994 Transforming growth factor- $\beta 1$, macrophage inflammatory protein- $1 \alpha$, and interleukin-8 gene expression is lower in stimulated human neonatal compared with adult mononuclear cells. Blood 84:118-124

5. Kilpatrick L, Harris MC 1997 Cytokines and the inflammatory response. In: Polin RA, Fox WW (eds) Fetal and Neonatal Physiology. WB Saunders, Philadelphia, pp 1967-1978

6. Liechty KW, Koenig JM, Mitchell MD, Romero R, Christensen RD 1991 Production of interleukin-6 by fetal and maternal cells in vivo during intraamniotic infection and in vitro after stimulation with interleukin-1. Pediatr Res 29:1-4 
7. Pillay V, Savage N, Laburn H 1994 Circulating cytokine concentrations and cytokine production by monocytes from newborn babies and adults. Pflugers Arch 428:197201

8. Rowen JL, Smith CW, Edwards MS 1995 Group B streptococci elicit leukotriene $B_{4}$ and interleukin- 8 from human monocytes: neonates exhibit a diminished response. J Infect Dis 172:420-426

9. Schibler KR, Liechty KW, White WL, Rothstein G, Christensen RD 1992 Defective production of interleukin- 6 by monocytes: a possible mechanism underlying several host defense deficiencies of neonates. Pediatr Res 31:18-21

10. Schibler KR, Trautman MS, Liechty KW, White WL, Rothstein G, Christensen RD 1993 Diminished transcription of interleukin-8 by monocytes from preterm neonates. J Leukoc Biol 53:399-403

11. Yachie A, Takano N, Ohta K, Uehara T, Fujita SI, Miyawaki T, Taniguchi N 1992 Defective production of interleukin-6 in very small premature infants in response to bacterial pathogens. Infect Immun 60:749-753

12. Dammann O, Leviton A 1997 Maternal intrauterine infection, cytokines, and brain damage in the preterm newborn. Pediatr Res 42:1-8

13. Gomez R, Romero R, Ghezzi F, Yoon BH, Mazor M, Berry SM 1998 The fetal inflammatory response syndrome. Am J Obstet Gynecol 179:194-202

14. Bagchi A, Viscardi RM, Taciak V, Ensor JE, McCrea KA, Hasday JD 1994 Increased activity of interleukin- 6 but not tumor necrosis factor- $\alpha$ in lung lavage of premature infants is associated with the development of bronchopulmonary dysplasia. Pediatr Res 36:244-252

15. Jones CA, Cayabyab RG, Kwong KYC, Stotts C, Wong B, Hamdan H, Minoo P, DeLemos RA 1996 Undetectable interleukin (IL)-10 and persistent IL-8 expression early in hyaline membrane disease: a possible developmental basis for the predisposition to chronic lung inflammation in preterm newborns. Pediatr Res 39:966-975

16. Yoon BH, Romero R, Yang SH, Jun JK, Kim IO, Choi JH, Syn HC 1996 Interleukin-6 concentrations in umbilical cord plasma are elevated in neonates with white matter lesions associated with periventricular leukomalacia. Am J Obstet Gynecol 174:1433-1440

17. Yoon BH, Romero R, Kim CJ, Koo JN, Choe G, Syn HC, Chi JG 1997 High expression of tumor necrosis factor- $\alpha$ and interleukin-6 in periventricular leukomalacia. Am J Obstet Gynecol 177:406-411

18. Astiz M, Saha D, Lustbader D, Lin R, Rackow E 1996 Monocyte response to bacterial toxins, expression of cell surface receptors, and release of anti-inflammatory cytokines during sepsis. J Lab Clin Med 128:594-600

19. Ertel W, Kremer JP, Kenney J, Steckholzer U, Jarrar D, Trentz O, Schildberg FW 1995 Downregulation of proinflammatory cytokine release in whole blood from septic patients. Blood 85:1341-1347

20. NIH Consensus Development Conference 1995 Effect of corticosteroids for fetal maturation and perinatal outcomes. Am J Obstet Gynecol 173:253-344

21. Schild PN, Charles BG 1994 Determination of dexamethasone in plasma of premature neonates using high-performance liquid chromatography. J Chromatogr B 658:189192

22. Berner R, Niemeyer CM, Leititis JU, Funke A, Schwab C, Rau U, Richter K, Tawfeek MS, Clad A, Brandis M 1998 Plasma levels and gene expression of granulocyte colony-stimulating factor, tumor necrosis factor-alpha, interleukin (IL)-1beta, IL-6, IL-8, and soluble intercellular adhesion molecule-1 in neonatal early onset sepsis. Pediatr Res 44:469-477
23. Kashlan F, Smulian J, Shen-Schwarz S, Anwar M, Hiatt M, Hegyi T 2000 Umbilical vein interleukin- 6 and tumor necrosis factor alpha plasma concentrations in the very preterm infant. Pediatr Infect Dis J 19:238-243

24. Jung T, Schauer U, Heusser C, Neumann C, Rieger C 1993 Detection of intracellular cytokines by flow cytometry. J Immunol Methods 159:197-207

25. Sander B, Andersson J, Andersson U 1993 Assessment of cytokines by immunofluorescence and the paraformaldehyde-saponin procedure. Immunol Rev 119:65-93

26. Schultz C, Reiss I, Rott C, Richter N, Gortner L, Bucsky P 1999 Intracytoplasmic detection of cytokines in neonatal lymphocytes and monocytes by flow cytometry. Blood 93:3566-3567

27. De Groote D, Zangerle PF, Gevaert Y, Fassotte MF, Beguin Y, Noizat-Pirenne F, Pirenne J, Gathy R, Lopez M, Dehart I, Igot D, Baudrihaye M, Delacroix D, Franchimont P 1992 Direct stimulation of cytokines (IL-1 $\beta$, TNF- $\alpha$, IL-6, IL-2, IFN- $\gamma$, and GM-CSF) in whole blood. I. Comparison with isolated PBMC stimulation. Cytokine 4:239-248

28. Munoz C, Misset B, Fitting C, Bleriot JP, Carlet J, Cavaillon JM 1991 Dissociation between plasma and monocyte-associated cytokines during sepsis. Eur J Immunol 21:2177-2184

29. Romero R, Gomez R, Ghezzi F, Yoon BH, Mazor M, Edwin SS, Berry SM 1998 A fetal systemic inflammatory response is followed by spontaneous onset of preterm parturition. Am J Obstet Gynecol 179:186-193

30. Yoon BH, Romero R, Jun JK, Park KH, Park JD, Ghezzi F, Kim BI 1997 Amniotic fluid cytokines (interleukin-6, tumor necrosis factor- $\alpha$, interleukin- $\beta$, and interleukin-8) and the risk for the development of bronchopulmonary dysplasia. Am J Obstet Gynecol 177:825-830

31. Yoon BH, Romero R, Park JS, Kim CJ, Kim SH, Choi JH, Han TR 2000 Fetal exposure to an intra-amniotic inflammation and the development of cerebral palsy at the age of three years. Am J Obstet Gynecol 182:675-681

32. Cai Z, Pan ZL, Pang Y, Evans OB, Rhodes PG 2000 Cytokine induction in fetal rat brains and brain injury in neonatal rats after maternal lipopolysaccharide administration. Pediatr Res 47:64-72

33. Brett FM, Mizisin AP, Powell HC, Campbell IL 1995 Evolution of neuropathologic abnormalities associated with blood-brain barrier breakdown in transgenic mice expressing interleukin-6 in astrocytes. J Neuropathol Exp Neurol 54:766-775

34. DeVries HE, Blom-Roosemalen MC, VanOsten M, DeBoer AG, VanBerkel TJ, Breimer DD, Kuiper J 1996 The influence of cytokines on the integrity of the blood-brain barrier in vitro. J Neuroimmunol 64:37-43

35. Saija A, Princi P, Lanza M, Scalese M, Aramnejad E, DeSarro A 1995 Systemic cytokine administration can affect blood-brain barrier permeability in the rat. Life Sci 56:775-784

36. Dammann O, Leviton A 1999 Brain damage in preterm newborns: might enhancement of developmentally regulated endogenous protection open a door for prevention? Pediatrics 104:541-550

37. Chheda S, Palkowetz KH, Garofalo R, Rassin DK, Goldman AS 1996 Decreased interleukin-10 production by neonatal monocytes and $\mathrm{T}$ cells: relationship to decreased production and expression of tumor necrosis factor- $\alpha$ and its receptors. Pediatr Res 40:475-483

38. Bancalari E, Abdenour GE, Feller R, Gannon J 1979 Bronchopulmonary dysplasia: clinical presentation. J Pediatr 95:819-823 